\title{
Fenton and Photo-Fenton Degradation of Reaktoset Brilliant Orange/P-2R and Telon Turquoise/M-GGL Dyes: Effect of Operating Parameters and Kinetic Study
}

\author{
Adife Seyda Yargic ${ }^{a, *}$, Nurgul Ozbay ${ }^{a}$ \\ ${ }^{a}$ Chemical and Process Engineering Department, Bilecik Şeyh Edebali University, \\ Bilecik, Turkey \\ seyda.guler@bilecik.edu.tr,nurgul.ozbay@bilecik.edu.tr
}

\begin{abstract}
In this study, decolorization of Reaktoset Brilliant Orange $P-2 R$ and Telon Turquoise $M$-GGL dyes in aqueous solution was investigated under Fenton $\left(\mathrm{H}_{2} \mathrm{O}_{2} / \mathrm{Fe}^{2+}\right)$ and photo-Fenton $\left(\mathrm{H}_{2} \mathrm{O}_{2} / \mathrm{Fe}^{2+} / U V\right)$ oxidation reactions. At first, batch experiments were carried out to determine the effects of ferric ion and hydrogen peroxide concentrations, as well as $\mathrm{pH}$ and mixing speed on the reaction rate to find optimum conditions. The experiments denoted that the decolorization efficiencies of Fenton and photo-Fenton processes were very close to each other for both dyes. During the second stage, the experimental data were analyzed by using the zero, first and second-order and Behnajady-Modirshahla-Ghanbery (BMG) kinetic models. BMG model provided the best correlation of the data. It was concluded that efficient color removals of Reaktoset Brilliant Orange P-2R and Telon Turquoise M-GGL dyes could be obtained when optimum conditions of Fenton and photo-Fenton oxidation processes were performed. In addition, the results could provide fundamental knowledge for the real industrial operators to effectively treat as mentioned dyes.
\end{abstract}

Keywords: Decolorization; Fenton process; Kinetics; Photo-Fenton process; Synthetic dyes

\section{INTRODUCTION}

Nowadays, large amounts of dye effluents are released to the environment due to the rapid growth of industry in most countries. Decolorization of dyes by efficient techniques is one of the major engineering aspects of the control technologies. Dyes are classified as azo, anthraquinone, triphenylmethane, arylmethane, acridine, heterocyclic, polymeric dyes, cyanine, or phthalocyanine etc. based on the chemical structure of the chromophoric group. Anthraquinone dyes have chromophore groups, $=\mathrm{C}=\mathrm{O}$ and $=\mathrm{C}=\mathrm{C}=$, and can be precipitated or adsorbed only in small amounts [1]. Azo-dyes contain the azo chromophoric group ( $-\mathrm{N}=\mathrm{N}-$ ) in addition to aromatic systems and auxochromes (such as $\mathrm{OH}$, $\mathrm{NH}_{2}, \mathrm{CO}_{2} \mathrm{H},-\mathrm{SO}_{3}$ and $\mathrm{Cl}$ ) [2]. Although azo dyes represent approximately $60-70 \%$ of all dyes used by the textile industry, anthraquinone dyes constitute the second largest class of textile dyes after azo dyes [1]. About a million tones of dyes are produced each year and nearly a half of this production contains azo dyes [3]. It is estimated that around $15 \%$ of the dye is lost during dyeing and finishing processes and is released in wastewaters [4]. The discharge of dye wastewater in the environment is described as very problematic to aquatic life and mutagenic to human [5]. Conventional techniques such as chemical coagulation/flocculation, ozonation, activated carbon adsorption, and biological treatment are used to treat the dye waste effluents [6]. Since many dyes are bio-recalcitrant, biological treatment is insufficient to degrade many dye compounds [7]. Moreover, these methods usually do not work efficiently as they are non-destructive, costly and merely involve the transfer of pollutants from water to sludge. By this way, the secondary waste appears and that needs further disposal [6]. These methods have technical and economical limitations because of the high cost, inefficiency for some soluble dyes, producing large amount of sludge, and resulting in higher pollution potential than the effluents because of the excessive use of chemicals [1]. Therefore, alternative technologies must be developed to overcome these problems. Alternatively, advanced oxidation processes (AOPs) such as homogeneous and heterogeneous photocatalysis are promising technologies which aim at the decolorization and mineralization of a wide range of dyes to stable inorganic compounds or, at least, their transformation into biodegradable or harmless products [2]. 
Among AOPs, Fenton process is very promising since this system achieves high reaction yields, offer a cost effective source of hydroxyl radicals and it is easy to operate and maintain [8]. Due to the low rates of reaction at reasonable $\mathrm{H}_{2} \mathrm{O}_{2}$ concentrations, oxidation of pollutants by $\mathrm{H}_{2} \mathrm{O}_{2}$ alone is not effective for high concentration of complex organic and inorganic compounds. Transition metal salts, ozone and UV-light can activate $\mathrm{H}_{2} \mathrm{O}_{2}$ to form hydroxyl radicals ( $\mathrm{HO} \bullet$ ). Fenton's reagent consists of ferrous iron and hydrogen peroxide. Hydrogen peroxide and ferrous ions are usually more stable in low $\mathrm{pH}$ values, initiate complex red-ox reactions and constitute highly reactive hydroxyl radicals [9]. The Fenton reagent has been found to be effective in treating various industrial wastewater components including aromatic amines [10] and a wide variety of dyes [11,12] as well as many other substances, e.g. pesticides [13,14] and surfactants $[15,16]$. Therefore, the Fenton reagent has been applied to treat a variety of wastes such as those associated with the textile and chemical industries [17]. Production of $\mathrm{HO} \cdot$ radicals by Fenton reagent occurs by means of addition of $\mathrm{H}_{2} \mathrm{O}_{2}$ to $\mathrm{Fe}^{2+}$ salts (Eq. (1)) [8]:

$\mathrm{Fe}^{2+}+\mathrm{H}_{2} \mathrm{O}_{2} \rightarrow \mathrm{Fe}^{3+}+\cdot \mathrm{OH}+\mathrm{OH}^{-}$

This reagent is an attractive oxidative system for wastewater treatment due to the fact that iron is very abundant and non-toxic element and hydrogen peroxide is easy to handle and environmentally safe [8]. The rate of organic pollutant degradation could be increased by irradiation with UV light (UV/Fenton process). UV light leads not only to the formation of additional hydroxyl radicals but also to recycling of ferrous catalyst by reduction of $\mathrm{Fe}^{3+}$ (Eqs. (2) and (3)). In this manner, $\mathrm{Fe}$ (II) concentration is increased and the overall reaction is accelerated [18]:

$\mathrm{H}_{2} \mathrm{O}_{2}+\mathrm{hv} \rightarrow \cdot \cdot \mathrm{OH}+\cdot \cdot \mathrm{OH}$

$\mathrm{Fe}^{3+}+\mathrm{H}_{2} \mathrm{O}+\mathrm{hv} \rightarrow \cdot \mathrm{OH}+\mathrm{Fe}^{2+}+\mathrm{H}^{+}$

Determination of optimum experimental conditions is essential for decolorization of dye wastewater by Fenton and photo-Fenton oxidation in an economic way. The main objectives of this study were $i$ ) to analyze $\mathrm{pH}$, hydrogen peroxide and ferrous dosage, and mixing speed effects on decolorization efficiencies of Reaktoset Brilliant Orange P-2R and Telon Turquoise M-GGL dyes by Fenton and photo-Fenton oxidation processes; ii) to determine the decolorization kinetics at optimal conditions of experimental parameters; iii) to establish the rate constants and correlation coefficients. Treatment studies of these dyes are not found in the literature, so the results can provide essential knowledge for the treatment of wastewater containing azo and anthraquinone dyes by Fenton and photo-Fenton oxidation processes.

\section{MATERIALS AND MeTHODS}

\subsection{Materials}

Reaktoset Brilliant Orange P-2R (Setaş) and Telon Turquoise M-GGL (Dystar) dyes were used without further purification. Telon Turquoise M-GGL dye is synthesized from chemical intermediates which form anthraquinone-like structures as its final state. The structure of Reaktoset Brilliant Orange $\mathrm{P}-2 \mathrm{R}$ dye is based on azobenzene $(\mathrm{Ph}-\mathrm{N}=\mathrm{N}-\mathrm{Ph})$. Their chemical structures, molecular formulas and molecular weights are demonstrated in Table 1. Reaktoset Brilliant Orange P-2R and Telon Turquoise M-GGL dyes were coded as AO33 and AB279, respectively. The initial concentrations of dyes for all experiments were $350 \mathrm{mg} / \mathrm{L}$. The dye oxidation was achieved by Fenton's reagent which was composed of a mixture of $\mathrm{FeSO}_{4} \cdot 7 \mathrm{H}_{2} \mathrm{O}$ (Merck) and $\mathrm{H}_{2} \mathrm{O}_{2}$ (Merck, 35\%). The $\mathrm{pH}$ of the reaction mixture was adjusted by adding $1 \mathrm{~N} \mathrm{NaOH}$ and $1 \mathrm{~N} \mathrm{H}_{2} \mathrm{SO}_{4}$ solutions. Distilled water from Nüve NS 108 purification system was used throughout this study. Reactions were triggered when hydrogen peroxide was added to reaction mixtures.

\subsection{Experimental Procedure}

Batch experiments for Fenton and photo-Fenton oxidation were performed in Lovibond Jar Test. The desired quantities of $\mathrm{Fe}^{2+}$ and $\mathrm{H}_{2} \mathrm{O}_{2}$ were added to $500 \mathrm{~mL}$ beakers containing dye solutions (350 $\mathrm{mg} / \mathrm{L}$ concentration). The Jar Test apparatus was proceed with rapid mixing of the reaction mixture at $300 \mathrm{rpm}$ for $1 \mathrm{~min}$, slow mixing at $100 \mathrm{rpm}$ for $30 \mathrm{~min}$, and then standstill for $30 \mathrm{~min}$. Solution $\mathrm{pH}$, $\mathrm{H}_{2} \mathrm{O}_{2}$ and $\mathrm{FeSO}_{4} \cdot 7 \mathrm{H}_{2} \mathrm{O}$ dosages, temperature and mixing speed effects on degradation efficiency (\%) were investigated. The kinetics of the oxidation was followed by taking samples at regular time intervals. UV-vis spectrums of dyes were recorded from 200 to $900 \mathrm{~nm}$ using Perkin Elmer Lambda $25 \mathrm{UV}$-Vis spectrophotometer. The maximum absorbance wavelength $\left(\lambda_{\max }\right)$ of AB279 and AO33 
Fenton and Photo-Fenton Degradation of Reaktoset Brilliant Orange/P-2R and Telon Turquoise/M-GGL Dyes: Effect of Operating Parameters and Kinetic Study

were found to be 620 and $496 \mathrm{~nm}$. The residual concentration of dyes in the solution was determined by measuring the absorption intensity at maximum absorbance wavelengths.

Degradation efficiency (\%) is calculated as follows [5]:

Degradation efficiency $(\%)=\left\lceil\left(C_{0}-C_{t}\right) / C_{0}\right\rceil * 100$

Where $C_{0}$ and $C_{t}$ are the concentrations of dye at reaction time 0 and t, respectively.

Table1. Chemical characteristics of AO33 and AB279 dyes

\begin{tabular}{|c|c|c|c|c|}
\hline Name & Chemical Structure & $\begin{array}{c}\text { Molecular } \\
\text { Formula }\end{array}$ & $\begin{array}{c}\begin{array}{c}\text { Molecular } \\
\text { weight }(\mathrm{g} / \mathrm{mol})\end{array} \\
\end{array}$ & $\begin{array}{l}\lambda_{\max } \\
(\mathbf{n m}) \\
\end{array}$ \\
\hline $\mathrm{AO} 33$ & & $\mathrm{C}_{34} \mathrm{H}_{28} \mathrm{~N}_{4} \mathrm{Na}_{2} \mathrm{O}_{8} \mathrm{~S}_{2}$ & 730.72 & 620 \\
\hline AB279 & & $\mathrm{C}_{22} \mathrm{H}_{17} \mathrm{~N}_{2} \mathrm{NaO}_{5} \mathrm{~S}$ & 444.44 & 496 \\
\hline
\end{tabular}

\subsection{Kinetic Models}

In this study, the decolorization kinetics of AB279 and AO33 dyes by Fenton and photo-Fenton oxidation processes were studied by using zero-order, first-order, second order and BehnajadyModirshahla-Ghanbery (BMG) reaction kinetics.

Zero-order reaction kinetics is defined as Eq. (5) [19]:

$d C_{t} / d t=-k_{0}$

First-order reaction kinetics is denoted as Eq. (6) [19, 20]:

$d C_{t} / d t=-k_{1} C_{t}$

Second order reaction kinetics is expressed as Eq. (7) [19, 20]:

$d C_{t} / d t=-k_{2}\left(C_{t}\right)^{2}$

where $k_{0}, k_{1}$ and $k_{2}$ are the apparent kinetic rate constants of zero-, first- and second-order kinetics, respectively; $t$ is the reaction time and $C_{t}$ is the concentration of AB279 or AO33 at any time. By integrating the Eqs. (8) - (10), the following equations could be achieved:

$C_{t}=C_{0}-k_{0} t$

$C_{t}=C_{0} \exp \left(-k_{1} t\right)$

$1 / C_{t}=1 / C_{0}+k_{2} t$

Behnajady-Modirshahla-Ghanbery (BMG) reaction kinetics is defined as Eq. (11) and (12) [20]:

$C_{t} / C_{0}=1-[t /(m+b t)]$

$t /\left[1-\left(C_{t} / C_{0}\right)\right]=m+b t$

Where $m$ and $b$ are two characteristic constants relating to oxidation capacities and reaction kinetics. A straight line with a slope of $b$ and an intercept of $m$ are obtained by plotting t versus $t /[1-$ $\left.\left(C_{t} / C_{0}\right)\right]$

\section{RESUlTS AND DisCUSSION}

\subsection{Effect of Initial $\mathrm{pH}$}

The effect of initial $\mathrm{pH}$ in the degradation of AB279 and AO33 dyes by Fenton and photo-Fenton oxidation processes was first studied. The experiments were carried out in the $\mathrm{pH}$ range of 2-7 and the results were shown in Fig. 1. When the initial pH increased from 2 to 4, the removal of AB279 color increased for both Fenton and photo-Fenton processes. The degradation efficiency decreased 
drastically, when the $\mathrm{pH}$ was higher than 4 . The degradation efficiencies of Fenton oxidation of dyes were rather low in alkaline medium while they were high in acidic medium as seen in Fig.1. This result is compatible with the literature where the acidic pH levels (approximately 3.5) are usually optimum for Fenton oxidation [20-22]. For photo-Fenton process the decolorization was minor than Fenton process at $\mathrm{pH}=3$, achieving a decolorization of $90.91 \%$ for $\mathrm{AB} 279$ and $66.47 \%$ for $\mathrm{AO} 33$ dye.

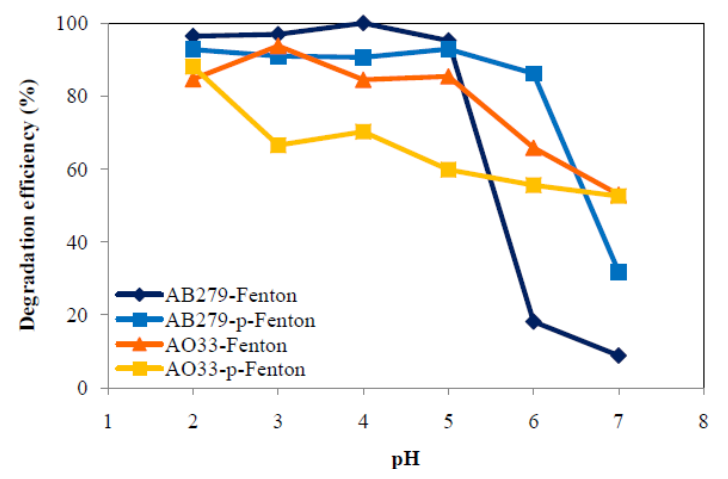

Fig1. Effect of $\mathrm{pH}$ on degradation of $\mathrm{AO} 33$ and $\mathrm{AB} 279$ dyes by Fenton and photo-Fenton processes

The minimum AB279 dye degradation efficiencies at $\mathrm{pH}=7$ were $8.80 \%$ and $31.82 \%$ for Fenton and photo-Fenton processes, respectively. This is due to the formation of ferrous/ferric hydroxide complexes lead to the deactivation of ferrous catalyst, which result in the amount of hydroxyl radical $(\bullet \mathrm{OH})$ generated was very small. At lower $\mathrm{pH}$ values, the oxonium ion $\left(\mathrm{H}_{3} \mathrm{O}_{2}{ }^{+}\right)$appeared according to the Eq. 13, this ion elevated the stability of $\mathrm{H}_{2} \mathrm{O}_{2}$ and limited the $\bullet \mathrm{OH}$ formation [19,23]. Hence, low degradation efficiency was observed at high and very low $\mathrm{pH}$ values. The $\mathrm{pH}$ value of 4 with $99.93 \%$ and $90.56 \%$ decolorization efficiencies was determined as the optimum for decolorization of AB279 dye by Fenton and photo-Fenton oxidation processes. Optimum $\mathrm{pH}$ values for AO33 dye decolorization were 3 and 2 for Fenton and photo-Fenton oxidation processes with $93.69 \%$ and 88.04\% decolorization efficiencies. The reduction in degradation efficiencies of AO33 dye was $40.72 \%$ for Fenton oxidation and $35.54 \%$ for photo-Fenton oxidation, when the $\mathrm{pH}$ of the reaction mixture was adjusted from optimum values to $\mathrm{pH}=8$.

$\mathrm{H}_{2} \mathrm{O}_{2}+\mathrm{H}^{+} \rightarrow \mathrm{H}_{3} \mathrm{O}_{2}^{+}$

\subsection{Effect of Ferrous Dosage}

The amount of $\mathrm{Fe}^{2+}$ is one of the main parameters affecting the Fenton and photo-Fenton processes. Effects of ferrous dosage on decolorization of AB279 and AO33 dyes were shown in Fig. 2. The experiments were conducted at different concentrations of $\mathrm{Fe}^{2+}$ from $20 \mathrm{mg} / \mathrm{L}$ to $100 \mathrm{mg} / \mathrm{L}$ at a constant $\mathrm{H}_{2} \mathrm{O}_{2}$ concentration of $60 \mathrm{mg} / \mathrm{L}$ and optimum initial $\mathrm{pH}$ values. The degradation efficiency increased with a higher initial ferrous concentration, this is because $\mathrm{Fe}^{2+}$ ions react with $\mathrm{H}_{2} \mathrm{O}_{2}$ generating more and more $\cdot \mathrm{OH}$ radicals which remove the dye by degrading it into smaller molecules [20,24]. In the presence of $80 \mathrm{mg} / \mathrm{L}$ of $\mathrm{Fe}^{2+}$ ion, a great improvement of the degradation of $\mathrm{AB} 279$ was observed with $93.35 \%$ and $95.19 \%$ degradation efficiencies for both Fenton and photo-Fenton processes. Although, by rising the ferrous dosage from $80 \mathrm{mg} / \mathrm{L}$ to $100 \mathrm{mg} / \mathrm{L}$ only a small decrease in degradation was established. It may be explained by red-ox reactions that $\bullet \mathrm{OH}$ radicals may be scavenged either by the reaction with $\mathrm{H}_{2} \mathrm{O}_{2}$ present or with another $\mathrm{Fe}^{2+}$ molecule to form $\mathrm{Fe}^{3+}[5,23]$. Maximum decolorization efficiencies of AO33 dye for Fenton (at $20 \mathrm{mg} / \mathrm{L} \mathrm{Fe}^{2+}$ dosage) and photoFenton (at $80 \mathrm{mg} / \mathrm{L} \mathrm{Fe}^{2+}$ dosage) processes were $89.90 \%$ and $99.09 \%$, respectively.

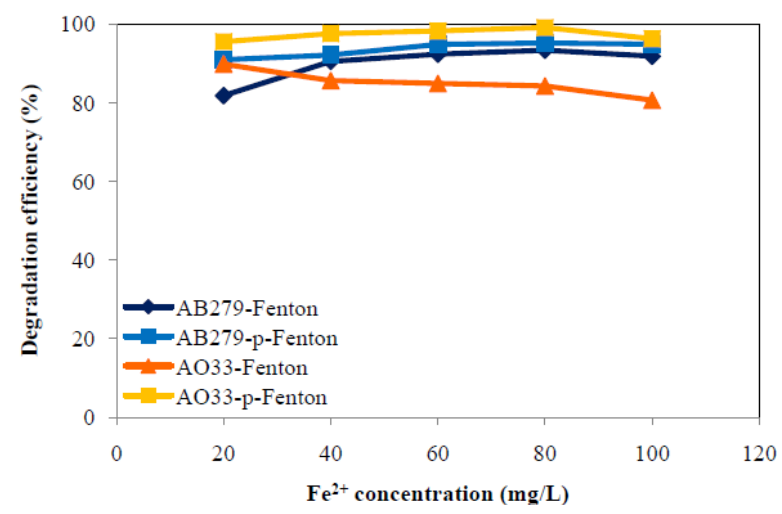

Fig2. Effect of ferrous dosage on degradation of $A O 33$ and $A B 279$ dyes by Fenton and photo-Fenton processes 


\subsection{Effect of $\mathrm{H}_{2} \mathrm{O}_{2}$ Dosage}

Degradation efficiencies of AB279 and AO33 dyes were given in Fig. 3 at different $\mathrm{H}_{2} \mathrm{O}_{2}$ dosages. pH of reaction mixtures and the ferrous dosages were used as optimum values. When the dosage of $\mathrm{H}_{2} \mathrm{O}_{2}$ was increased from $10 \mathrm{mg} / \mathrm{L}$ to $80 \mathrm{mg} / \mathrm{L}$ for $\mathrm{AB} 279$ removal by Fenton process, the degradation efficiency was not changed considerably and it was also balanced at $299 \%$. Relative results were obtained for AO33 dye. This situation indicates that $\mathrm{H}_{2} \mathrm{O}_{2}$ alone is not effective in the removal of color [25]. $20 \mathrm{mg} / \mathrm{L} \mathrm{H}_{2} \mathrm{O}_{2}$ was chosen both in decolorization of $\mathrm{AB} 279$ and $\mathrm{AO} 33$ as optimum in the subsequent experiments.

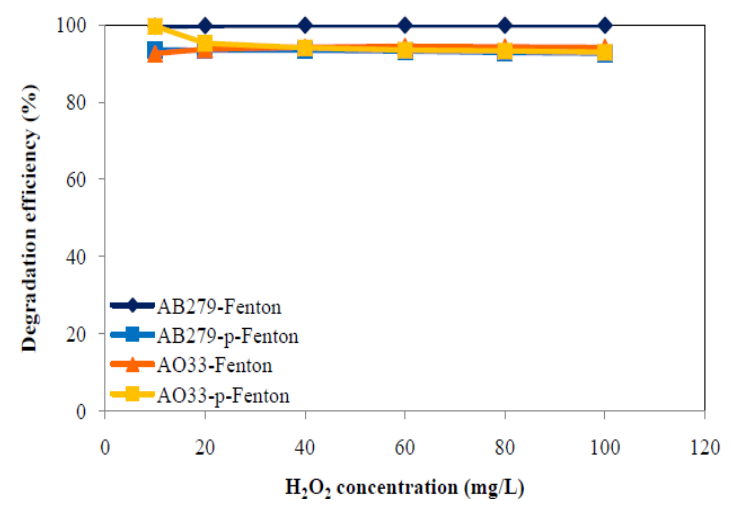

Fig3. Effect of hydrogen peroxide dosage on degradation of $A O 33$ and $A B 279$ dyes by Fenton and photo-Fenton processes

\subsection{Effect of Mixing Speed}

Effects of mixing speed on Fenton and photo-Fenton oxidation process were illustrated in Fig. 4. The mixing speed was studied between 25 and $250 \mathrm{rpm}$. The dosages of $\mathrm{Fe}^{2+}$ and $\mathrm{H}_{2} \mathrm{O}_{2}$ were adjusted as optimum values for both AB279 and AO33 dyes. As can be seen from Fig. 4, the mixing speed did not considerably affect the decolorization of dyes. The degradation efficiency (\%) of AB279 dye for Fenton process changed between 91.86 and $94.28 \%$. Mixing speed of $100 \mathrm{rpm}$ and $250 \mathrm{rpm}$ were identified as optimal values for Fenton and photo-Fenton oxidation of AB279 dye. $250 \mathrm{rpm}$ and 150 rpm were determined as optimum mixing speeds for Fenton and photo-Fenton oxidation of AO33 dye with degradation efficiencies of 95.81 and $98.32 \%$, respectively.

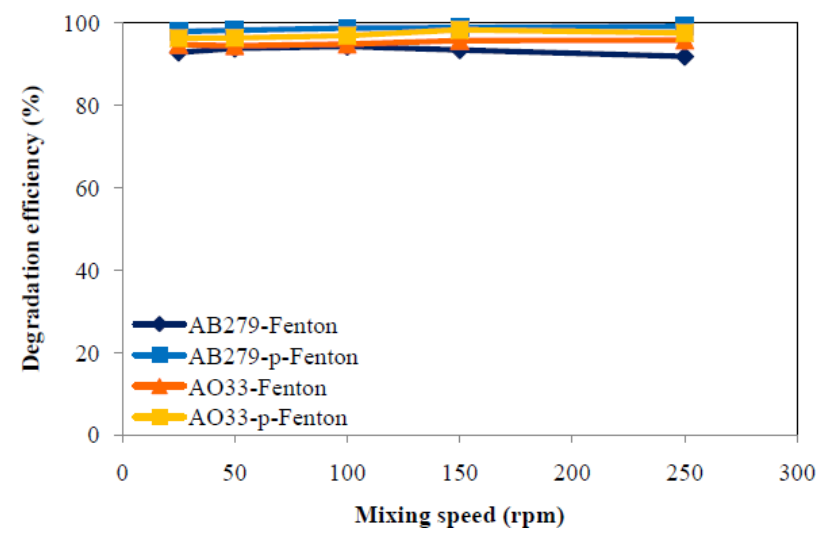

Fig4. Effect of mixing speed on degradation of AO33 and AB279 dyes by Fenton and photo-Fenton processes

\subsection{Kinetic Study}

Reaction kinetics was evaluated for a better understanding of degradation process of dye molecules. The results of zero-, first-, second-order and BMG kinetic models were given in Fig. 5 and Table 2. According to correlation coefficient values, the BMG kinetic model was found to fit the experimental data well with higher $\mathrm{R}^{2}$ values than zero-, first- and second-order kinetic models. The physical meaning of $1 / \mathrm{m}$ was the initial dye discoloration rate in the process. The faster initial discoloration rate of dye could be obtained with the higher $1 / \mathrm{m}$ value. When $\mathrm{t}$ was long and approaching infinity, the $1 / \mathrm{b}$ value indicated the theoretical maximum dye discoloration fraction, which was equal to the maximum oxidation capacity of Fenton process at the end of reaction [26]. 


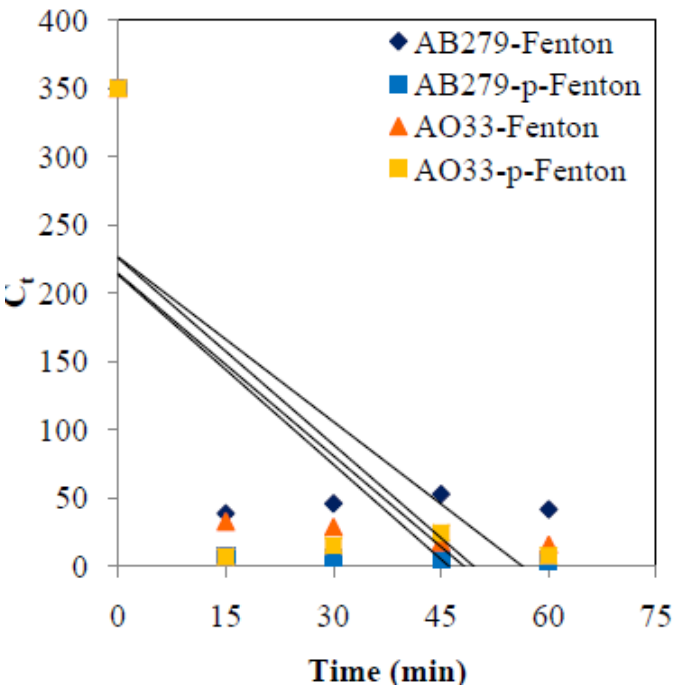

(a)

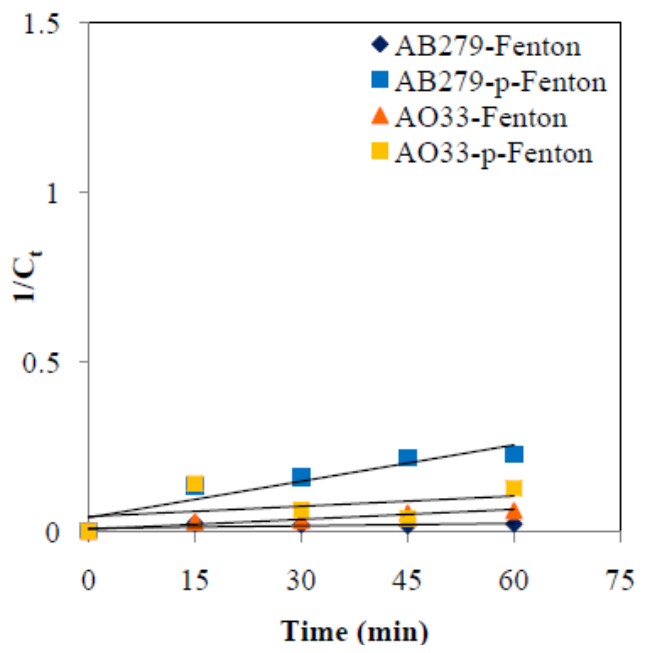

(c)

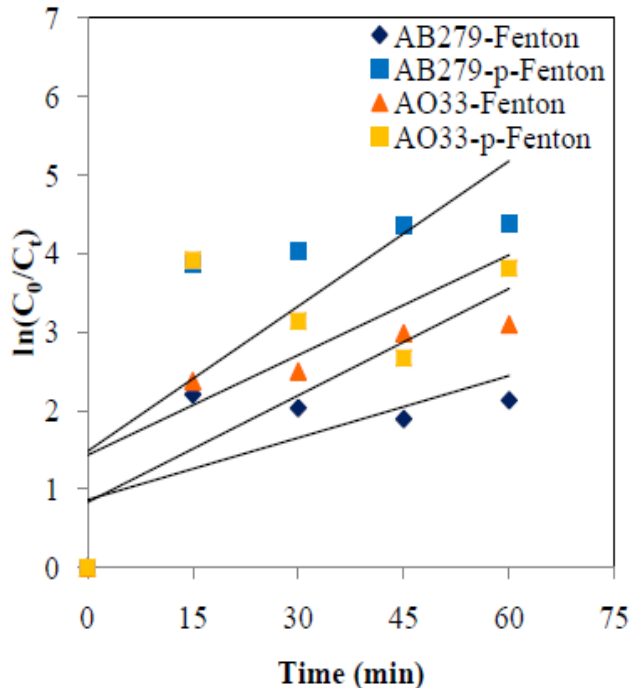

(b)

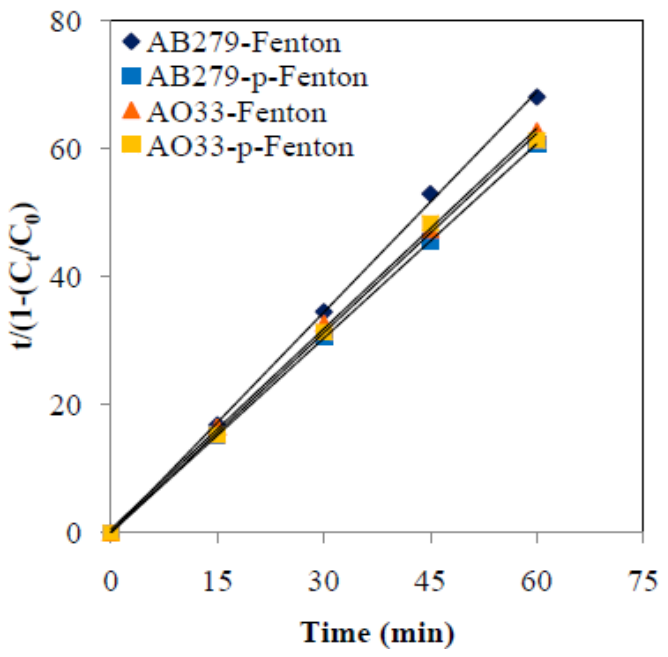

(d)

Fig5. (a) Zero-order, (b) first-order, (c) second-order, (d) BMG kinetic models for AO33 and AB279 dyes by Fenton and photo-Fenton processes

Table2. The kinetic parameters of Fenton and Photo-Fenton oxidation processes for the decolorization of AO33 and $A B 279$

\begin{tabular}{|c|c|c|c|c|c|c|c|c|c|}
\hline \multirow[b]{2}{*}{$\begin{array}{l}\text { Dye and } \\
\text { process }\end{array}$} & \multicolumn{2}{|c|}{ Zero-order model } & \multicolumn{2}{|c|}{ First-order model } & \multicolumn{2}{|c|}{ Second-order model } & \multicolumn{3}{|c|}{ BMG model } \\
\hline & $\begin{array}{c}\mathbf{k}_{0} \\
\left(\mathrm{mg} \mathrm{L}^{-1} \min ^{-1}\right)\end{array}$ & $\mathbf{R}^{2}$ & $\begin{array}{c}\mathrm{k}_{1} \\
\left(\min ^{-1}\right)\end{array}$ & $\mathbf{R}^{2}$ & $\begin{array}{c}\mathrm{k}_{2} \\
\left(\mathrm{~L} \mathrm{mg}^{-1} \min ^{-1}\right)\end{array}$ & $\mathbf{R}^{2}$ & $1 / \mathrm{m}$ & 1/b & $\mathbf{R}^{2}$ \\
\hline $\begin{array}{l}\text { AB279- } \\
\text { Fenton }\end{array}$ & 4.017 & 0.486 & 0.026 & 0.449 & 0.000 & 0.368 & 31.25 & 0.871 & 0.999 \\
\hline $\begin{array}{l}\text { AB279- } \\
\text { p-Fenton }\end{array}$ & 4.626 & 0.507 & 0.061 & 0.609 & 0.003 & 0.864 & 11.91 & 0.989 & 1.000 \\
\hline $\begin{array}{l}\text { AO33- } \\
\text { Fenton }\end{array}$ & 4.554 & 0.546 & 0.045 & 0.725 & 0.001 & 0.943 & 1.71 & 0.959 & 0.999 \\
\hline $\begin{array}{l}\text { AO33-p- } \\
\text { Fenton }\end{array}$ & 4.447 & 0.490 & 0.042 & 0.398 & 0.001 & 0.161 & 83.33 & 0.962 & 0.998 \\
\hline
\end{tabular}

\section{Conclusion}

In this work, decolorization capacities of Fenton and photo-Fenton oxidation processes were investigated by changing initial $\mathrm{pH}$ of the reaction mixture, ferrous and hydrogen peroxide dosages, and mixing speed. $\mathrm{pH}$ of the reaction mixture was the fundamental parameter which controlled the production of hydroxyl free radical and the concentration of ferrous ions. Optimum operating parameters can be summarized as: i) Reaktoset Brilliant Orange P-2R decolorization by Fenton oxidation process: $\mathrm{pH}=3, \mathrm{H}_{2} \mathrm{O}_{2}$ dosage $=20 \mathrm{mg} / \mathrm{L}, \mathrm{Fe}^{2+}$ dosage $=20 \mathrm{mg} / \mathrm{L}$, and mixing speed $=250$ 
$\mathrm{rpm}$; ii) Reaktoset Brilliant Orange P-2R decolorization by photo-Fenton oxidation process: $\mathrm{pH}=2$, $\mathrm{H}_{2} \mathrm{O}_{2}$ dosage $=20 \mathrm{mg} / \mathrm{L}, \mathrm{Fe}^{2+}$ dosage $=80 \mathrm{mg} / \mathrm{L}$, and mixing speed $=150 \mathrm{rpm}$; iii) Telon Turquoise M-GGL degradation by Fenton oxidation process: $\mathrm{pH}=4, \mathrm{H}_{2} \mathrm{O}_{2}$ dosage $=20 \mathrm{mg} / \mathrm{L}, \mathrm{Fe}^{2+}$ dosage $=80$ $\mathrm{mg} / \mathrm{L}$, and mixing speed $=100 \mathrm{rpm}$; $i v$ ) Telon Turquoise M-GGL degradation by photo-Fenton oxidation process: $\mathrm{pH}=4, \mathrm{H}_{2} \mathrm{O}_{2}$ dosage $=20 \mathrm{mg} / \mathrm{L}, \mathrm{Fe}^{2+}$ dosage $=80 \mathrm{mg} / \mathrm{L}$, and mixing speed $=250$ rpm. Fenton process lead to more than $90 \%$ decolorization of Reaktoset Brilliant Orange P-2R and Telon Turquoise M-GGL dyes in relatively short time ( 15 min). The kinetic study indicated that the decolorization kinetics of Reaktoset Brilliant Orange P-2R and Telon Turquoise M-GGL followed the BMG kinetic model with higher $\mathrm{R}^{2}$ values $\left(\mathrm{R}^{2}>0.998\right)$ compared to zero-, first- and second-order kinetic models.

It is known that Fenton and photo-Fenton oxidation processes are very effective and less expensive than conventional processes. Furthermore, experimental results clearly verify that both Fenton and photo-Fenton processes can be used to treat water discharge containing dyes such as Reaktoset Brilliant Orange P-2R and Telon Turquoise M-GGL with higher degradation efficiency $(\sim 99 \%)$.

\section{ACKNOWLEDGEMENTS}

Authors would like to thank Yaprak KARA for all her help.

\section{REFERENCES}

[1] Liu L., Zhang J., Tan Y., Jiang Y., Hu M., Li S. and Zhai Q., Rapid decolorization of anthraquinone and triphenylmethane dye using chloroperoxidase: Catalytic mechanism, analysis of products and degradation route, Chem. Eng. J. 244, 9-18 (2014).

[2] Elmorsi T.M., Riyad Y.M., Mohamed Z.H. and Abd El Bary H.M.H., Decolorization of Mordant red 73 azo dye in water using $\mathrm{H}_{2} \mathrm{O}_{2} / \mathrm{UV}$ and photo-Fenton treatment, J. Hazard. Mater. 174, 352-358 (2010).

[3] Sun J.H., Shi S.H., Lee Y.F. and Sun S.P., Fenton oxidative decolorization of the azo dye Direct Blue 15 in aqueous solution, Chem. Eng. J. 155, 680-683 (2009).

[4] Ersöz G., Fenton-like oxidation of Reactive Black 5 using rice husk ash based catalyst, Appl. Catal. B: Environ. 147, 353-358 (2014).

[5] Lucas M.S. and Peres J.A., Degradation of Reactive Black 5 by Fenton/UV-C and ferrioxalate $/ \mathrm{H}_{2} \mathrm{O}_{2} /$ solar light processes, Dyes Pigments 74, 622-629 (2007).

[6] Gaan P.P. and Li S.F.Y., Efficient removal of Rhodamine B using a rice hull-based silica supported iron catalyst by Fenton-like process, Chem. Eng. J. 229, 351-363 (2013).

[7] Merouani S., Hamdaoui O., Saoudi F., Chiha M. and Petrier C., Influence of bicarbonate and carbonate ions on sonochemical degradation of Rhodamine B in aqueous phase, J. Hazard. Mater. 175, 593-599 (2010).

[8] Papic S., Vujevic D., Koprivanac N. and Sinko D., Decolourization and mineralization of commercial reactive dyes by using homogeneous and heterogeneous Fenton and UV/Fenton processes, J. Hazard. Mater. 164, 1137-1145 (2009).

[9] Karatas M., Argun Y.A. and Argun M.E., Decolorization of antraquinonic dye, eactive Blue 114 from synthetic wastewater by Fenton process: Kinetics and thermodynamics, J. Ind. Eng. Chem. 18, 1058-1062 (2012).

[10] Casero I., Sicilia D., Rubio S. and Pérez-Bendito D., Chemical degradation of aromatic amines by Fenton's reagent, Water. Res. 31, 1985-1995 (1997).

[11] Kuo W.G., Decolorizing dye wastewater with Fenton's reagent, Water. Res. 26, 881-886 (1992).

[12] Nam S., Renganathan V. and Tratnyek P.G., Substituent effects on azo dye oxidation by the $\mathrm{Fe}^{\mathrm{III}}-\mathrm{EDTA}-\mathrm{H}_{2} \mathrm{O}_{2}$ system, Chemosphere 45, 59-65 (2001).

[13] Huston P.L. and Pignatello J.J., Degradation of selected pesticide active ingredients and commercial formulations in water by the photo-assisted Fenton reaction, Water. Res. 33, 12381246 (1999).

[14] Barbusiński K. and Filipek K., Use of Fenton's reagent for removal of pesticides from industrial wastewater, Pol. J. Environ. Stud. 10(4), 207-212 (2001).

[15] Lin S.H., Lin C.M. and Leu H.G., Operating characteristics and kinetic studies of surfactant wastewater treatment by Fenton oxidation, Water. Res. 33, 1735-1741 (1999). 
[16] Kitis M., Adams C.D. and Daigger G., The effects of Fenton's reagent pretreatment on the biodegradability of nonionic surfactants, Water. Res. 33, 2561-2568 (1999).

[17] Barbusiński K., The Modified Fenton Process for Decolorization of Dye Wastewater, Pol. J. Environ. Stud. 14(3), 281-285 (2005).

[18] Grčić I., Papić S., Mesec D., Koprivanac N. and Vujević D., The kinetics and efficiency of UV assisted advanced oxidation of various types of commercial organic dyes in water, J. Photoch. Photobio. A 273, 49-58 (2014).

[19] Sun S.P., Li C.J., Sun J.H., Shi S.H., Fan M.H. and Zhou Q., Decolorization of an azo dye Orange $\mathrm{G}$ in aqueous solution by Fenton oxidation process: Effect of system parameters and kinetic study, J. Hazard. Mater. 161, 1052-1057 (2009).

[20] Ertugay N. and Acar F.N., Removal of COD and color from Direct Blue 71 azo dye wastewater by Fenton's oxidation: Kinetic study, Arabian J. Chem. xxx, xxx-xxx (2013). Article in press.

[21] Ramirez J.H., Duarte F.M., Martins F.G., Costa C.A. and Madeira L.M., Modelling of the synthetic dye Orange II degradation using Fenton's reagent: From batch to continuous reactor operation, Chem. Eng. J. 148, 394-404 (2009).

[22] Walling C., Fenton's reagent revisited, Acc. Chem. Res. 8, 125-131 (1975).

[23] Lucas M.S. and Peres J.A., Decolorization of the azo dye Reactive Black 5 by Fenton and photoFenton oxidation, Dyes Pigments 71, 236-244 (2006).

[24] Fu F., Wang Q. and Tang B., Effective degradation of C.I. Acid Red 73 by advanced Fenton process, J. Hazard. Mater. 174, 17-22 (2010).

[25] Kang S.F., Liao C.H. and Chen M.C., Pre-oxidation and coagulation of textile wastewater by the Fenton process, Chemosphere 46, 923-928 (2002).

[26] Xu H.Y., Shi T.N., Wu L.C. and Qi S.Y., Discoloration of Methyl Orange in the Presence of Schorl and $\mathrm{H}_{2} \mathrm{O}_{2}$ : Kinetics and Mechanism, Water, Air, Soil Pollut. 224(10), 1-11 (2013).

\section{AUTHORS' BIOGRAPHY}

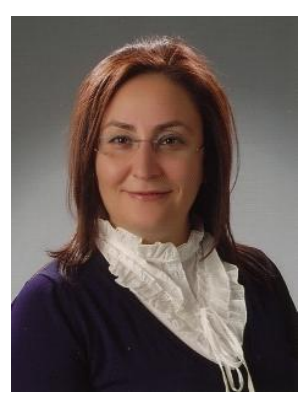

Prof. Dr. Nurgül ÖZBAY, is Dean of Engineering Faculty; and Professor in Chemical and Process Engineering Department, Bilecik Şeyh Edebali University, Turkey. She obtained her PhD in Analytic Chemistry Department "Pyrolysis of Cotton Seed Cake and Characterization of Liquid Products". Her research interest include biomass, activated carbon, porous materials, high pressure synthesis of carbonaceous materials, catalyst preparation and their characterization, liquefaction of biomass, pyrolysis, wastewater treatment, heavy metal and dye sorption, advanced oxidation processes, statistical analyses. She has published many research papers in academic journals.

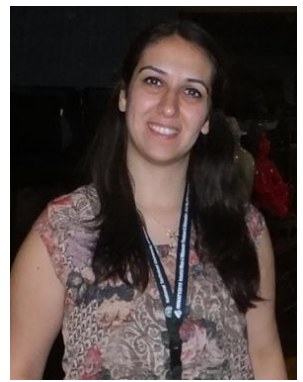

Res. Assist. Adife Şeyda YARGIÇ, is a PhD candidate working with Prof. Dr. Nurgül ÖZBAY at Chemical and Process Engineering Department, Bilecik Şeyh Edebali University, Turkey. Her research interest include biomass, activated carbon, porous materials, high pressure synthesis of carbonaceous materials , catalyst preparation and their characterization, liquefaction of biomass, pyrolysis, wastewater treatment, heavy metal and dye sorption, advanced oxidation processes, statistical analyses. She has been studying on her doctoral thesis about "synthesis and characterization of carbon foam from biomass". 